\title{
Global perspectives on physical and nonphysical discipline: A Bayesian multilevel analysis
}

\author{
Andrew Grogan-Kaylor, ' Berenice Castillo, '® Garrett T. Pace,' \\ Kaitlin P. Ward, 'Julie Ma, ${ }^{2}$ Shawna J. Lee,' and \\ Heather Knauer'
}

\begin{abstract}
Background and Objective: Sixty countries worldwide have banned the use of physical punishment, yet little is known about the association of physical and nonphysical forms of child discipline with child development in a global context. The objective of this study is to examine whether physical punishment and nonphysical discipline are associated with child socioemotional functioning in a global sample of families from 62 countries and whether country-level normativeness of physical punishment and nonphysical discipline moderated those associations. Methods: Data for this study are from 215,885 families in the fourth and fifth rounds of the United Nations Children's Fund Multiple Indicator Cluster Surveys. Bayesian multilevel logistic models were used to analyze the associations of physical punishment and nonphysical discipline (i.e., taking away privileges and verbal reasoning) with three different outcomes representing children's socioemotional functioning: getting along well with other children, aggression, and becoming distracted. Results: The use of physical punishment was not associated with getting along with other children, was associated with increased aggression, and was associated with increases in distraction. Taking away privileges was associated with lower levels of getting along with other children, higher levels of aggression, and higher levels of becoming distracted. Verbal reasoning (i.e., explaining why a behavior was wrong) was associated with higher levels of getting along with other children, higher levels of aggression, and higher levels of becoming distracted. Country-level normativeness moderated some of these associations but in general the direction of effects was consistent. Conclusions: Results suggest that eliminating physical punishment would benefit children across the globe and align with the United Nations Convention on the Rights of the Child, which calls for all children to be free from physical violence. More attention needs to be focused on the associations of nonphysical forms of discipline with child functioning across the globe.
\end{abstract}

\section{Keywords}

Parenting, harsh discipline, socioemotional, discipline, cross-country

\section{Introduction}

Protecting children from violence and adverse experiences that increase the risk of poor socioemotional development is a global public health priority (World Health Organization, 2016). The World Health Organization has identified socioemotional health as an important domain of early childhood development that has a lasting impact on children's developmental trajectories (Irwin et al., 2007). Social and emotional functioning encompass both interpersonal processes (i.e., relating and interacting with others, developing empathy) and intrapersonal processes (i.e., regulating and expressing one's emotions). Social competence and emotional well-being in early childhood are intricately related to cognitive development and collectively provide a foundation for academic success and overall well-being in later years (National Scientific Council on the Developing Child, 2004). The family environment is a critical context of early childhood development (Irwin et al., 2007), and exposure to violence, including parental physical punishment, is associated with poorer child socioemotional functioning (Britto et al., 2017; Herrenkohl et al., 2016).' In low- and middleincome countries (LMICs), nearly half of the children are at risk of not meeting their developmental potential, in part due to adverse environments and experiences (Black et al., 2017).

\section{Physical Punishment}

Globally, violence against children is remarkably common (Hillis et al., 2016). One of the most common forms of violence against children is physical punishment. In a study of nine countries, over $50 \%$ of children had experienced slapping, hitting, or spanking by an adult family member within the past month (Lansford et al., 2010). In another study, $43 \%$ of children in LMICs had been spanked in the previous month, and across 59 of the 62 LMICs in

\footnotetext{
' University of Michigan-Ann Arbor, USA

${ }^{2}$ University of Michigan-Flint, USA
}

\section{Corresponding author:}

Andrew Grogan-Kaylor, School of Social Work, University of Michigan-Ann Arbor, 1080 South, University Avenue, Ann Arbor, MI 48109, USA.

Email: agrogan@umich.edu 
the study, spanking was negatively associated with 3- and 4-yearolds' socioemotional functioning (Pace et al., 2019). The results of Pace et al.'s study are in accord with a large meta-analytic review of 50 years of research on physical punishment, which found that physical punishment of children was associated with a wide range of undesirable behavioral and mental health outcomes (Gershoff \& Grogan-Kaylor, 2016b). On the strength of the evidence base showing the harm physical punishment causes to child development and human dignity, the United Nations Convention of the Rights of the Child (UNCRC) recognizes physical punishment as a violation of children's basic right to be free from all forms of violence (Durrant et al., 2019). Following the UNCRC's strong recommendation to implement legislative measures that prohibit physical punishment, 60 countries have legally protected children from physical punishment in all settings, including the child's home (United Nations Children's Fund [UNICEF], 2020).

\section{Nonphysical Discipline}

While the UNCRC has recognized that physical punishment is a violation of children's rights, little is known about what forms of parental discipline are most suitable as alternatives. Nonphysical discipline strategies include the use of positive or negative verbal reprimand as well as privilege restriction. Another form of nonphysical discipline is verbal reasoning, where the parent explains to the child why their behavior is inappropriate. Few studies have examined nonphysical forms of discipline and their associations with child socioemotional functioning in a global context, particularly with reference to whether a particular form of nonphysical discipline is more or less normative in that country (Lansford et al., 2012).

\section{Cultural Normativeness}

One common argument in the parenting literature is that cultural context is a key factor in the extent to which various parenting behaviors are associated with positive or negative outcomes for children. Specifically, researchers have referenced this argument in regard to physical punishment, arguing that physical punishment may be less harmful to children in contexts in which it is more "normative" (e.g., used more frequently or general societal attitudes are more favorable toward physical punishment). One study that examined cultural normativeness and parental physical punishment in a sample of 6- to 17-year-olds in six countries (China, India, Italy, Kenya, Philippines, and Thailand) found significant country-level variation in the extent to which physical punishment was normative. However, perceived normativeness did not moderate the association between physical punishment and higher levels of child aggression (Lansford et al., 2005). Another study of 8- to 12 -year-olds in the same six countries reported similar results, in that there was cultural variation in the degree to which parent discipline practices were perceived by mothers to be normative. However, overall, perceived normativeness of the discipline technique only slightly moderated the associations between parenting and child well-being (Gershoff et al., 2010). The current study extends this literature by focusing on the question of whether country-level normativeness of three disciplinary practices is a moderator of the associations between parental discipline and child socioemotional functioning.

\section{Bayesian Approaches to the Study of Parenting}

Most parenting research utilizes a frequentist statistical approach, which shows whether there is enough evidence to reject the null hypothesis. If the evidence is not sufficient to reject the null, the researcher concludes to "failed to reject" the null. However, this does not imply that the researcher accepts the null hypothesis. Under a Bayesian statistical test, the null and alternative hypotheses may be similar to frequentist hypotheses (i.e., $\mathrm{H}_{0}: \bar{x}=0$ and $\mathrm{H}_{\mathrm{a}}$ : $\bar{x} \neq 0$ ); however, the interpretation of results is different. Instead of rejecting or failing to reject the null hypothesis, Bayesian estimation provides the probability for the particular estimated parameter values, given the data at hand. For example, when testing moderation-such as whether cultural normativeness moderates the relationship between parental discipline and child socioemotional functioning-Bayesian model comparisons can provide a more straightforward way of accepting the null hypothesis (Kruschke \& Liddell, 2018) or of comparing two alternative hypotheses (Jarosz \& Wiley, 2014).

Additionally, under a Bayesian paradigm, instead of a confidence interval, the researcher is given a credible interval, meaning that there is a $95 \%$ probability of the population value falling within that interval. Therefore, a researcher using Bayesian statistics could potentially accept either the null or alternative hypotheses and draw substantive conclusions that reflect the actual associations between the variables. Bayesian statistics also enable researchers to take prior empirical findings (priors) into account when estimating parameters. This may be important and useful when researchers are attempting to build upon a knowledge base.

\section{Current Study}

Using a Bayesian approach on data from 62 LMICs, this study provides a global perspective on the associations of caregivers' use of physical punishment and nonphysical discipline (i.e., taking away privileges and verbal reasoning) with child socioemotional functioning. We further examine whether the frequency that each of these forms of discipline were used in a particular country (countrylevel normativeness) is related to the degree to which a particular form of discipline was associated with child socioemotional functioning.

\section{Method}

\section{Sample and Procedures}

We used cross-sectional population-based data from the Multiple Indicator Cluster Surveys (MICS). The UNICEF implements the MICS surveys in LMICs to inform policy making on issues related to women and children. The surveys began in 1995. By February 2019, 117 countries had participated in at least one round of data collection. Each round includes a set of standard survey questions. Our analysis was inclusive of the 62 countries who participated in MICS4 (2009-2013) and MICS5 (2012-2017), during which our variables of interest were assessed.

Household members completed multiple surveys. The head of household or another adult completed the first survey, providing information about the household and its members. Most often $(83 \%$ in our study), this survey was completed by a male head of household. After a household roster was completed, an interviewer randomly selected a child in the household. This child was the 
reference child for a module with questions about discipline of children aged 2-14 years (MICS5 also included 1-year-olds). The household respondent was asked whether they, or anyone in the household, had disciplined the child in certain ways in the past month. After this survey was completed, mothers completed a questionnaire about socioemotional functioning for each of their children younger than 5 years of age. We merged parent discipline survey data from the household survey with the child development survey data. We included 62 countries in our analytic sample with equivalent measurements for our variables of interest.

Given that mothers provided assessment of child socioemotional functioning only for children younger than 5 years, we limited our analytic sample to children aged 36-59 months. We also limited our sample to households that were not missing child socioemotional functioning data. After inclusion criteria, our analytic sample consisted of 215,885 children. The average sample across countries was 3,482 children. The smallest sample size for a country was Barbados $(n=193)$; the largest was Nigeria $(n=20,451)$.

\section{Measures}

Outcome. We examined three separate outcomes measuring child socioemotional functioning, one of the domains of MICS's Early Childhood Development Index (ECDI). MICS used data from three countries to pilot test and validate the ECDI (Loizillon et al., 2017). Our three dependent variables were whether the child (1) gets along well with other children; (2) kicks, bites, or hurts other children or adults (i.e., aggression); and (3) gets distracted easily ( $1=$ yes, $0=$ no). Each of these indicators was dichotomous and was reported by the caregiver.

Disciplinary strategies. We measured three disciplinary strategies in this analysis: physical punishment, taking away privileges, and verbal reasoning $(1=$ yes, $0=n o)$. Use of physical punishment was measured by caregiver self-reports of whether they or anyone in their household had spanked, hit, or slapped the child on the bottom with a bare hand in the previous month. Taking away privileges was assessed by asking the household respondent whether any adult in the household had taken away privileges, forbidden something the child liked, or had not allowed the child to leave the house in the previous month. Verbal reasoning was measured by asking the household respondent whether any adult in the household had explained to the child why their behavior was wrong in the previous month. Measures of the normativeness of these three types of discipline were created by calculating country-specific means for the usage of each of the disciplinary strategies.

Covariates. In our analysis, we included child age and sex, whether the respondent was the child's biological parent, respondent sex, mother's level of education (none, primary, secondary, or more), number of household members, household wealth score (standardized by country), and whether the child lived in an urban or rural area as covariates.

\section{Analysis}

To adjust for the correlation of observations within countries, we employed a Bayesian multilevel logistic regression model (Burkner, 2017, 2018; McGlothlin \& Viele, 2018). Our model took this form:

$$
\begin{aligned}
y_{i j}= & \beta_{0}+\beta_{1} \text { physical punishment }+\beta_{2} \text { taking away privileges } \\
& +\beta_{3} \text { verbal reasoning } \\
& +\beta_{4} \text { country-level frequency of physical punishment } \\
& +\beta_{5} \text { country-level frequency of taking away privileges } \\
& +\beta_{6} \text { country-level frequency of verbal reasoning } \\
& +\beta_{7} \text { physical punishment } \\
& \times \text { country level frequency of physical punishment } \\
& +\beta_{8} \text { taking away privileges } \\
& \times \text { country level frequency of taking away privileges } \\
& +\beta_{9} \text { verbal reasoning } \\
& \times \text { country level frequency of verbal reasoning } \\
& +\Sigma \beta_{k} \text { covariates }_{k}+u_{0 j},
\end{aligned}
$$

Here, $y_{i j}$ represents the log odds of each outcome for child $i$ in country $j$. $\beta_{0}$ is an intercept term. $\beta_{1-3}$ are regression coefficients for the association of different forms of discipline with our outcome of interest. $\beta_{4-6}$ represent regression coefficients associated with country-level means of those disciplinary strategies, and $\beta_{7-9}$ are the respective interaction terms. These interaction terms assessed whether the association of a particular form of discipline with child socioemotional functioning was moderated by the frequency with which that form of discipline was used in a particular country. $\Sigma \beta_{k}$ represents a set of regression coefficients showing the association of other covariates with the outcome. $u_{0 j}$ is a country-specific random intercept.

Exploratory analysis provided some prior information about the range and size of regression coefficients. We therefore used normal regression priors with wide variation $(\beta \sim N(0,5))$ for the regression coefficients to improve estimation of the model (Gelman, 2007; Van de Schoot et al., 2014). Bayesian multilevel analyses were conducted using R (R Core Team, 2018), the package brms (Burkner, 2017, 2018), and the Stan Core Library (Stan Development Team, 2018) for Bayesian analyses.

\section{Results \\ Descriptive Statistics}

Table 1 presents results from descriptive statistics. Overall, $80 \%$ of caregivers in this sample used physical punishment, $47 \%$ took away privileges, and $43 \%$ used verbal reasoning in the past month.

\section{Bayesian Multilevel Models}

Initial analysis showed that the unconditional intraclass correlation coefficient - the amount of variation attributable to the nesting of participants in countries - was $13.5 \%$ for getting along with other children, $11.9 \%$ for aggression, and $9.3 \%$ for distraction.

Regression coefficients. As presented in Table 2, the use of physical punishment was not credibly associated with getting along with children and was associated with higher levels of aggression and distraction. Taking away privileges was associated with lower levels of getting along with other children and higher levels of aggression and distraction. Verbal reasoning was associated with higher levels of getting along with other children and higher levels of aggression and was not credibly associated with distraction. 
Table I. Study Descriptive Statistics or Descriptive Statistics on Study Participants.

\begin{tabular}{|c|c|c|c|c|}
\hline Variable & Mean or \% & Standard Deviation & Minimum & Maximum \\
\hline Physical punishment & 0.43 & 0.50 & 0.00 & 1.00 \\
\hline Taking away privileges & 0.47 & 0.50 & 0.00 & 1.00 \\
\hline Verbal reasoning & 0.80 & 0.40 & 0.00 & 1.00 \\
\hline Child age in months & 47.30 & 6.86 & 36.00 & 59.00 \\
\hline Male child & $51 \%$ & 0.50 & 0.00 & 1.00 \\
\hline Household respondent is child's father or mother & $74 \%$ & 0.44 & 0.00 & 1.00 \\
\hline Household respondent is male & $83 \%$ & 0.37 & 0.00 & 1.00 \\
\hline Number of household members & 6.95 & 4.02 & 2.00 & 50.00 \\
\hline Household wealth score & -0.12 & 0.97 & -10.11 & 7.30 \\
\hline Urban residence & $41 \%$ & 0.49 & 0.00 & 1.00 \\
\hline Multiple Indicator Cluster Surveys round & 4.56 & 0.50 & 4.00 & 5.00 \\
\hline Mother's educational level & 2.03 & 0.83 & 1.00 & 3.00 \\
\hline
\end{tabular}

Note. $n=215,885$. Household wealth score is in standard deviation units and standardized within each country.

Table 2. Bayesian Multilevel Model of Associations of Discipline and Socioemotional Functioning or Bayesian Multilevel Model of Associations of Discipline and Functioning.

\begin{tabular}{|c|c|c|c|c|c|c|c|c|c|}
\hline \multirow[b]{2}{*}{ Measure } & \multicolumn{3}{|c|}{$\begin{array}{l}\text { Model I: Gets along w/ } \\
\text { others }\end{array}$} & \multicolumn{3}{|c|}{$\begin{array}{c}\text { Model 2: Kicks, bites, or hits } \\
\text { others }\end{array}$} & \multicolumn{3}{|c|}{ Model 3: Gets distracted } \\
\hline & $\begin{array}{l}\text { Estimate } \\
\text { (est. error) }\end{array}$ & $\begin{array}{l}\mathrm{LCl} \\
95 \%\end{array}$ & $\begin{array}{l}\mathrm{UCl} \\
95 \%\end{array}$ & $\begin{array}{l}\text { Estimate } \\
\text { (est. error) }\end{array}$ & $\begin{array}{l}\mathrm{LCl} \\
95 \%\end{array}$ & $\begin{array}{l}\mathrm{UCl} \\
95 \%\end{array}$ & $\begin{array}{l}\text { Estimate } \\
\text { (est. error) }\end{array}$ & $\begin{array}{l}\mathrm{LCl} \\
95 \%\end{array}$ & $\begin{array}{l}\mathrm{UCl} \\
95 \%\end{array}$ \\
\hline Physical punishment & $0.00(0.02)$ & -0.03 & 0.03 & $0.33(0.01)$ & 0.31 & 0.35 & $0.15(0.01)$ & 0.13 & 0.17 \\
\hline Country mean of physical punishment & $-\mathrm{I} .60(0.75)$ & -3.08 & -0.14 & $2.17(0.54)$ & 1.12 & 3.23 & $-0.78(0.73)$ & -2.22 & 0.65 \\
\hline Taking away privileges & $-0.11(0.02)$ & -0.14 & -0.07 & $0.11(0.01)$ & 0.09 & 0.13 & $0.09(0.01)$ & 0.07 & 0.11 \\
\hline Country mean of taking away privileges & $-0.55(0.7 \mathrm{I})$ & -1.96 & 0.82 & $-0.82(0.52)$ & -1.86 & 0.18 & $\mathrm{I} .74(0.70)$ & 0.37 & 3.10 \\
\hline Verbal reasoning & $0.28(0.02)$ & 0.24 & 0.32 & $0.04(0.01)$ & 0.02 & 0.07 & $0.02(0.01)$ & -0.00 & 0.05 \\
\hline Country mean of verbal reasoning & $0.99(1.13)$ & -1.23 & 3.20 & $-4.04(0.81)$ & -5.62 & -2.42 & $-0.57(1.10)$ & -2.73 & 1.61 \\
\hline Child age & $0.01(0.00)$ & 0.01 & 0.01 & $-0.01(0.00)$ & -0.01 & -0.01 & $-0.00(0.00)$ & -0.00 & -0.00 \\
\hline Male child & $-0.24(0.01)$ & -0.27 & -0.21 & $0.30(0.01)$ & 0.28 & 0.32 & $0.04(0.01)$ & 0.02 & 0.06 \\
\hline Household respondent is child's mother or father & $0.04(0.02)$ & 0.00 & 0.08 & $-0.00(0.01)$ & -0.03 & 0.02 & $-0.05(0.01)$ & -0.07 & -0.02 \\
\hline Household respondent is male & $0.02(0.02)$ & -0.03 & 0.06 & $-0.07(0.01)$ & -0.10 & -0.04 & $-0.01(0.01)$ & -0.04 & 0.02 \\
\hline Number of household members & $-0.01(0.00)$ & -0.01 & -0.01 & $0.01(0.00)$ & 0.01 & 0.02 & $0.00(0.00)$ & -0.00 & 0.00 \\
\hline Household wealth score & $0.13(0.01)$ & 0.11 & 0.15 & $-0.04(0.01)$ & -0.05 & -0.02 & $-0.05(0.01)$ & -0.07 & -0.04 \\
\hline Urban residence & $-0.10(0.02)$ & -0.14 & -0.07 & $-0.00(0.01)$ & -0.03 & 0.02 & $0.04(0.01)$ & 0.01 & 0.06 \\
\hline Multiple Indicator Cluster Round & $-0.33(0.03)$ & -0.39 & -0.27 & $-0.27(0.02)$ & -0.31 & -0.23 & $0.04(0.01)$ & 0.01 & 0.08 \\
\hline Mother's education level & $0.15(0.01)$ & 0.12 & 0.17 & $-0.00(0.01)$ & -0.02 & 0.01 & $0.01(0.01)$ & -0.01 & 0.02 \\
\hline Physical Punishment $\times$ Country Mean of Physical Punishment & $1.06(0.15)$ & 0.77 & 1.36 & $0.00(0.09)$ & -0.17 & 0.18 & $0.11(0.09)$ & -0.07 & 0.29 \\
\hline $\begin{array}{l}\text { Taking Away Privileges } \times \text { Country Mean of Taking Away } \\
\text { Privileges }\end{array}$ & $0.42(0.10)$ & 0.22 & 0.61 & $-0.15(0.07)$ & -0.28 & -0.02 & $0.03(0.07)$ & -0.10 & 0.16 \\
\hline Verbal Reasoning $\times$ Country Mean of Verbal Reasoning & $0.64(0.20)$ & 0.25 & 1.02 & $-0.09(0.13)$ & -0.35 & 0.17 & $0.08(0.13)$ & -0.17 & 0.33 \\
\hline
\end{tabular}

Note. $n=215,885$. $\mathrm{LCl}=$ lower credible interval; $\mathrm{UCl}=$ upper credible interval.

Country-specific mean levels of the use of different discipline strategies had varying associations with child socioemotional functioning. The country-level mean of physical punishment was associated with lower levels of children getting along with other children, suggesting that in countries where physical punishment is more common, children were less likely to get along with other children. The country-level mean for physical punishment was positively associated with aggression, suggesting that in countries where physical punishment is more prevalent, levels of child aggression are higher. The country-level mean of physical punishment was not associated with child distraction. Additionally, the country-level mean of taking away privileges was not credibly associated with getting along with other children or with aggression but was associated with higher levels of distraction. Lastly, the country-level mean of verbal reasoning was not associated with getting along with other children, nor with distraction, but was associated with lower levels of aggression, suggesting that aggression is, on average, lower in countries with higher mean levels of verbal reasoning.

There were also varying associations of the interaction of the three discipline strategies and the country-level usage of the disciplinary strategies (i.e., normativeness) with child socioemotional functioning. In the model for getting along with other children, there was a statistically credible interaction of individual use of physical punishment and the country-level mean of physical punishment, suggesting that physical punishment had less of an effect on this outcome in countries where it was more common. In contrast, in the model for aggression, the credible intervals of the interaction term included zero, suggesting that physical punishment had an equivalent effect across countries. Similarly, in the model 
for distraction, there was no credible interaction, suggesting that physical punishment had equivalent effects across countries. With regard to taking away privileges, there were some statistically credible interactions. In the model for getting along with other children, there was a positive interaction, suggesting that the effect of taking away privileges was weaker in countries where it was more common. In the model for aggression, there was a negative interaction, again, suggesting that the association of taking away with aggression was weaker in countries where it was more common. None of the interaction terms of taking away privileges at the family and country levels were statistically credible in the models for distraction. This suggests that the associations of taking away privileges on child outcomes were consistent across countries. Lastly, in the model for getting along with other children, there was a positive interaction, suggesting that verbal reasoning might be more beneficial in countries where it was more common. There were no credible interactions of verbal reasoning at the family and country levels in the models for aggression and distraction, suggesting that the verbal reasoning was associated with lower levels of aggression and distraction, regardless of country-level normativeness.

As presented in Table 2, male children had poorer functioning across all three outcome domains than female children. Greater household wealth scores were associated with higher child socioemotional functioning across all three outcome domains. Urban residence was associated with lower levels of getting along with other children and was associated with greater levels of distraction. Higher levels of maternal education were associated with higher child socioemotional functioning, although the effect size was small. Participation in a more recent MICS round was associated with lower levels of getting along with other children, lower aggression, and greater distraction.

There was credible variation in the random intercept of all three logistic regression models (Table 2), suggesting that the degree of all three domains of child socioemotional functioning varied by country.

\section{Discussion}

Across cultures, representing nearly one third of the world's countries, our analysis found consistent evidence that physical punishment and taking away privileges put children at risk for adverse socioemotional functioning, whereas verbal reasoning may promote some aspects of child socioemotional functioning, such as getting along with others. The effects of physical punishment on child aggression and distraction did not vary by country-level normativeness. These findings join an accumulating body of literature that shows the associations of physical punishment and negative child outcomes regardless of the context in which children are disciplined, including country (Pace et al., 2019), race and ethnicity (Gershoff \& Grogan-Kaylor, 2016a), and neighborhood (Ma et al., 2020). On average, taking away children's privileges was associated with lower levels of child socioemotional functioning.

Verbal reasoning was associated with higher levels of getting along with others; this association was stronger in countries where verbal reasoning was more normative. Interestingly, verbal reasoning also increased aggression and this finding did not vary by normativeness, albeit this association was the smallest of the three forms of discipline. These findings suggest that verbal reasoning, as measured in the MICS study, may have both positive and negative effects on children's socioemotional development. However, it is important to consider the context in which verbal reasoning is utilized. Empirical research that can incorporate the context of verbal reasoning may help assess the effects of verbal reasoning as a form of discipline. For example, the negative effects of verbal reasoning may be due to punitive tones and language. Alternatively, verbal reasoning may have negative effects on children if it is not employed in a way that is developmentally appropriate for the child to understand why their behavior is inappropriate.

On average, taking away children's privileges was associated with decreased odds of getting along with others and increased odds of aggression and distraction. These effects varied by cultural normativeness, in that taking away privileges was less deleterious in countries where this discipline strategy was more normative. These results suggest that the effectiveness of taking away privileges may be dependent on how normative this form of discipline is within the country. However, overall, our results posit that taking away privileges may not be beneficial for children's development. This may be because this discipline strategy fails to teach children proper interpersonal skills subsequent to conflict. Or, it may be that parents tend to take away privileges in an aggressive manner and tone, making it more likely for children to model this aggression. Future researchers should continue to explore the effectiveness of taking away privileges to determine why this strategy may not be effective, particularly in LMICs.

Looking across the three socioemotional outcomes (Figures 13 ), our findings are consistent with the perspective that reducing physical discipline strategies is more likely to promote positive outcomes for children. Notably, the substantive effect of physical punishment on aggression and distraction was largest in the LMICs in this study, followed by taking away privileges and verbal reasoning. These findings suggest that children's experience of parental use of physical punishment, which may likely involve coercive parent-child interactions, has a larger association with adverse child outcomes than nonphysical discipline. Our findings also confirm prior literature that the use of nonphysical discipline strategies such as verbal reasoning can be effective in promoting positive socioemotional outcomes. In the LMICs included in this study, verbal reasoning had the strongest, positive association with getting along with other children. On the other hand, the overall association between physical punishment and getting along with other children was zero, suggesting that physical punishment is not linked to children's prosocial behavior in LMICs.

\section{Limitations}

All study data were collected from in-person interviews. Concern for social desirability may have led respondents to underreport socially undesirable behaviors, such as physical punishment. While Bayesian analysis enables a direct interpretation of the relationship between discipline and children's development from a global perspective, causal attributions cannot be made from cross-sectional analyses. Additionally, the present analyses cover a limited developmental time period in children's lives and do not address whether these associations would hold over time. Another limitation is that the measure of parental discipline was based on three dichotomous items that do not capture all forms of parental discipline. In addition, because a large number of countries with cultural variance are involved in MICS, there are methodological challenges in defining and assessing complex domains of child socioemotional 


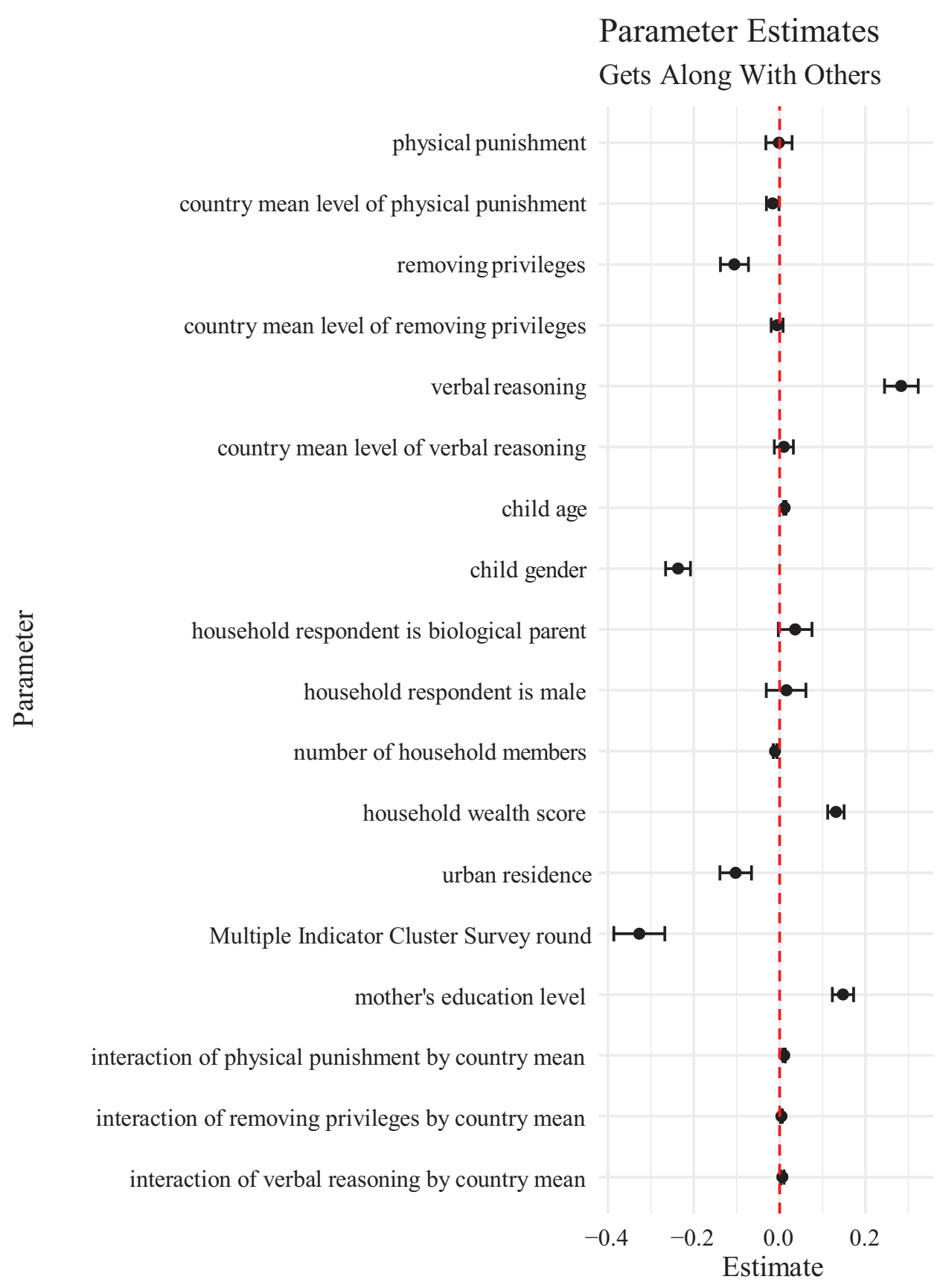

Country Level Variables Are Rescaled to Show Effect of 1\% Change

Figure I. Associations of Disciplinary Strategies With Gets Along With Others.

Note. $n=215,885$.

functioning and parenting behavior. For example, cultural norms may affect parental perceptions of their child's socioemotional functioning, and parents may have implemented certain disciplinary practices such as withdrawal of privileges and verbal reasoning inappropriately or in a coercive and abusive manner. Lastly, we note that while mothers completed the child development modules, most of the respondents to the MICS household survey were male ( $83 \%$ in the present study). While this provides an alternative perspective to many studies, which rely on female reporters, it is possible that male respondents may have less knowledge of the disciplinary strategies employed in the household than do female respondents.

\section{Implications for Policy and Intervention}

The notion that physical punishment is associated with reductions in child socioemotional functioning is consistent with a child rightsbased perspective beginning with the Declaration of the Rights of the Child (United Nations [UN] General Assembly, 1959). The UN 


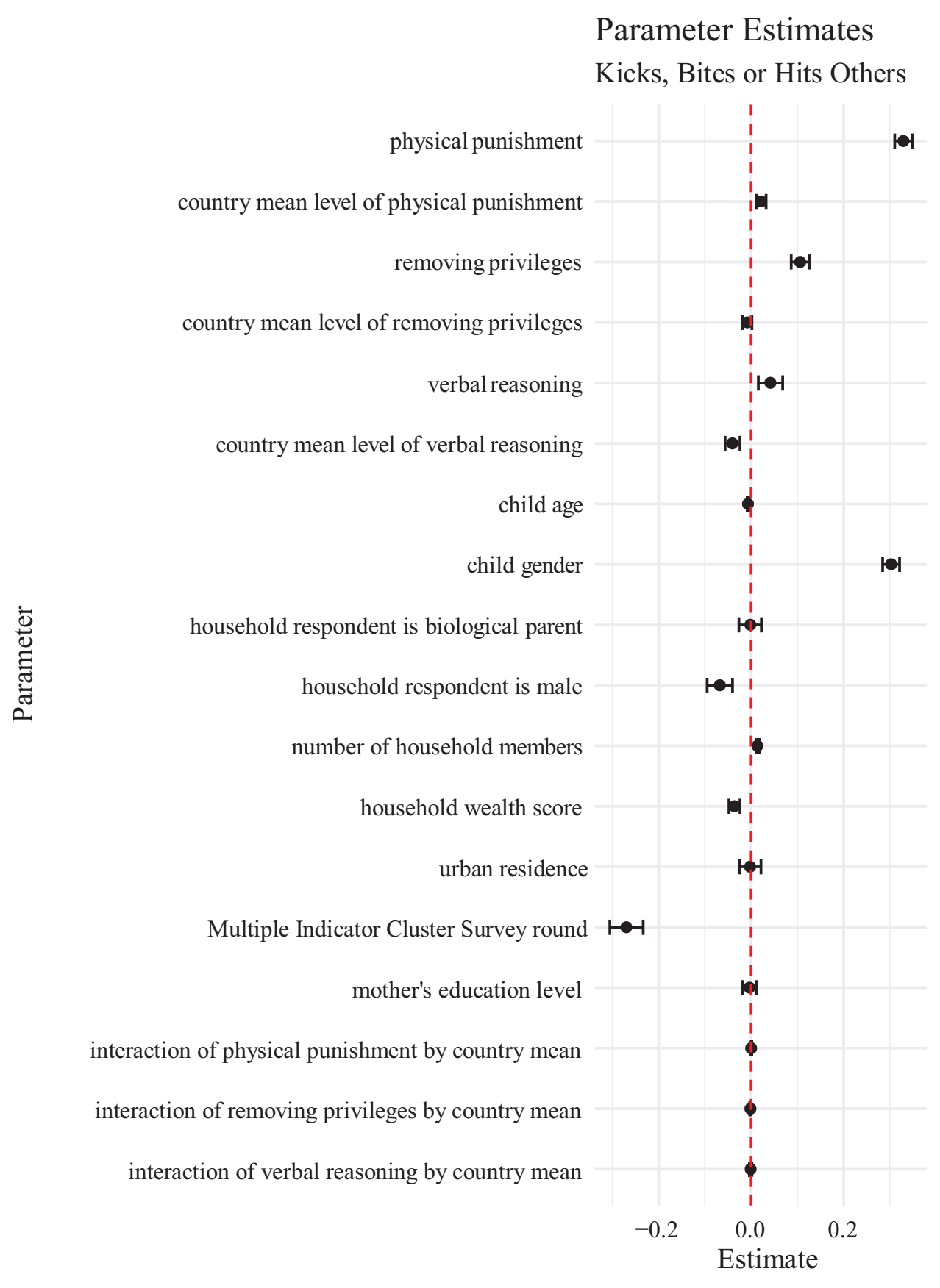

Country Level Variables Are Rescaled to Show Effect of 1\% Change

Figure 2. Associations of Disciplinary Strategies With Kicks, Bites, or Hits Others.

Committee on the Rights of the Child General Comment No. 8 (2006) advises states to protect children from all forms of violence, including "corporal punishment and other cruel or degrading forms of punishment" (UN General Assembly, 1989). The UN Secretary-General's Study on Violence Against Children urged the elimination of physical punishment (Pinheiro, 2006), and these suggestions were endorsed by a resolution of the UN General Assembly (2007). In 2015, all UN member states adopted the 2030 Sustainable Development Agenda, which includes ending all forms of violence against children (Sustainable Development Goal 16.2). To date, 60 countries have enacted a prohibition on the use of physical punishment (End Violence Against Children, n.d.).

Interventions targeting families can communicate the potential harms of physical punishment and provide parents with resources enabling them to employ more positive disciplinary strategies such as communicating expectations and verbal reasoning about children's misbehavior (Durrant, 2016). Overall, research provides evidence that positive parenting practices, including expressing love, warmth, and emotional support, are associated with improvements in children's well-being cross-culturally (Khaleque \& Rohner, 2011). 


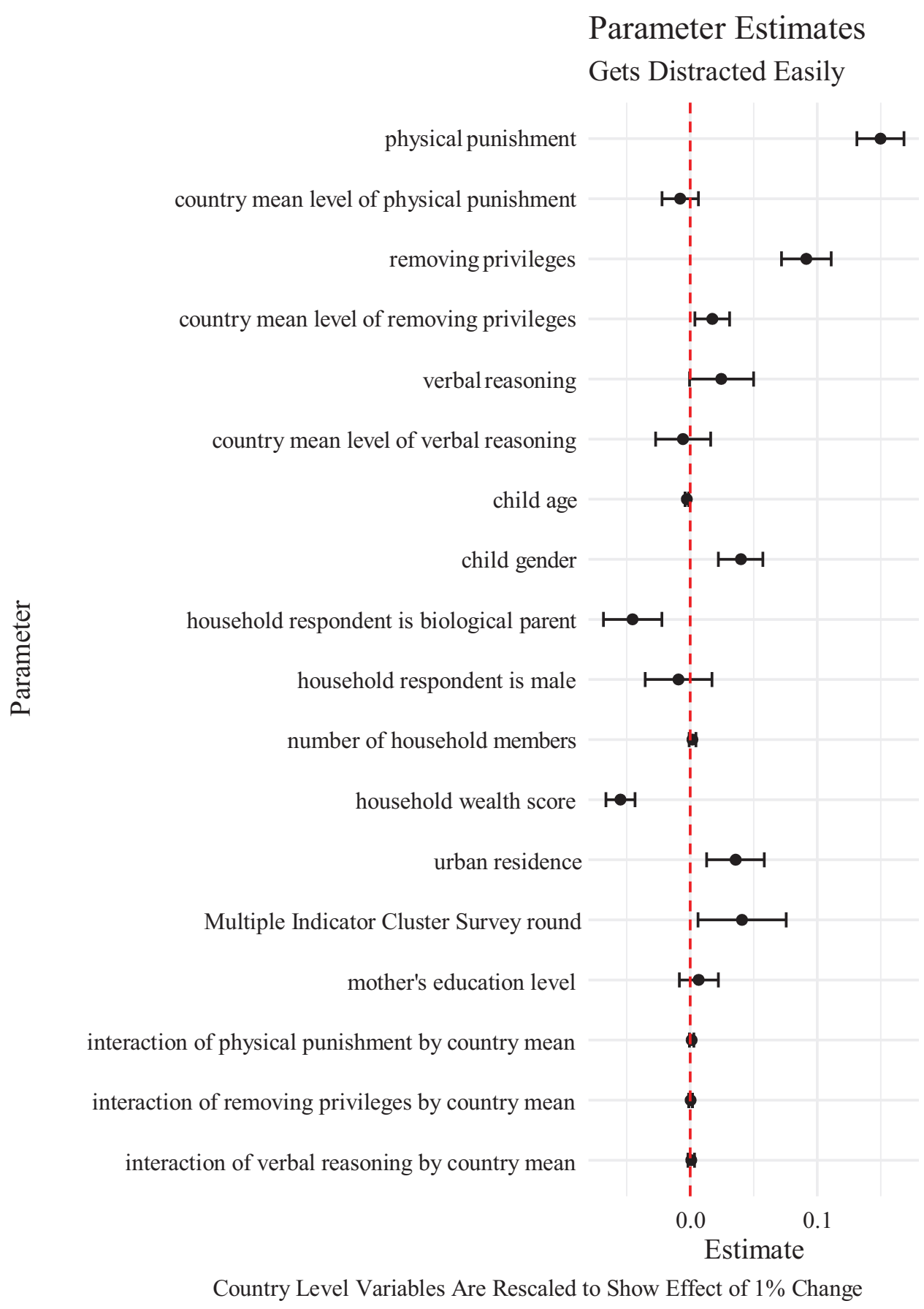

Figure 3. Associations of Disciplinary Strategies With Gets Distracted Easily.

\section{Implications for Future Research}

Although evidence suggests that physical punishment is linked to adverse child socioemotional functioning, the influences of other forms of discipline studied remain more varied. Our findings suggest that country-level normativeness of discipline strategies may influence the relationship between some forms of discipline and child outcomes, which is consistent with prior research (Gershoff et al., 2010). It may be that culture - over and above normativeness of parenting behaviors-plays a larger role in the meaning and outcomes of some other forms of discipline than is the case with physical punishment. Thus, future research would benefit from further exploration of how culture influences nonphysical disciplinary practices.

\section{Conclusion}

Using a Bayesian approach with a global sample of 215,885 children, this study provides rigorous evidence of the relationship of 
three forms of discipline with child socioemotional functioning. Overall, physical punishment was associated with lower levels of socioemotional functioning. Taking away privileges showed a similar relationship to lower levels of socioemotional functioning. Verbal reasoning showed a positive relationship to socioemotional functioning. Country-level normativeness moderated some of these associations. These results align with growing recognition that all children have the right to be protected from physical violence (Durrant et al., 2019) and that eliminating all forms of physical punishment in homes, schools, and other settings is necessary to promote the well-being of children.

\section{Acknowledgments}

This research was supported in part through computational resources and services provided by Advanced Research Computing at the University of Michigan, Ann Arbor. In particular, we greatly appreciate the support of Ryan Bankston and Bennet Fauber in teaching us about these resources and facilitating their use.

\section{Funding}

The author(s) received no financial support for the research, authorship, and/or publication of this article.

\section{ORCID iD}

Berenice Castillo (D) https://orcid.org/0000-0002-9652-5885

\section{References}

Black, M. M., Walker, S. P., Fernald, L. C. H., Andersen, C. T, DiGirolamo, A. M, Lu, C., McCoy, D. C., Fink, G., Shawar, Y. R., Shiffman, J., Devercelli, A. E., Wodon, Q. T., Vargas-Barón, E., Grantham-McGregor, S., \& Lancet Early Childhood Development Series Steering Committee. (2017). Early childhood development coming of age: Science through the life course. The Lancet, 389(10064), 77-90. https://doi.org/10.1016/S0140-6736(16)313 $89-7$

Britto, P. R., Lye, S. J., Proulx, K., Yousafzai, A. K., Matthews, S. G., Vaivada, T., Perez-Escamilla, R., Rao, N., Ip, P., Fernald, L. C. H., MacMillan, H., Hanson, M., Wachs, T. D., Yao, H., Yoshikawa, H., Cerezo, A., Leckman, J. F., Bhutta, Z. A., \& Early Childhood Development Interventions Review Group, for the Lancet Early Childhood Development Series Steering Committee. (2017). Nurturing care: Promoting early childhood development. The Lancet, 389(10064), 91-102. https://doi.org/10.1016/S0140-6736(16)313 90-3

Burkner, P.-C. (2017). Brms: An R package for Bayesian multilevel models using stan. Journal of Statistical Software, 80(1), 1-28. https://doi.org/10.18637/jss.v080.i01

Burkner, P.-C. (2018). Advanced Bayesian multilevel modeling with the R package brms. The R Journal, 10(1), 395-411.

Durrant, J. E. (2016). Positive discipline in everyday parenting (4th ed.). Save the Children Sweden. https://resourcecentre.savethechildren. net/library/positive-discipline-everyday-parenting-pdep-fourthedition

Durrant, J. E., Steward-Tufescu, A., \& Afifi, T. O. (2019). Recognizing the child's right to protection from physical violence: An update on progress and a call to action. Child Abuse \& Neglect, 104297.

End Violence Against Children. (n.d.). Ending corporal punishment. Retrieved from https://www.end-violence.org/ending-corporalpunishment
Gelman, A. (2007). A Bayesian formulation of exploratory data analysis and goodness-of-fit testing. International Statistical Review, 71(2), 369-382.

Gershoff, E. T., \& Grogan-Kaylor, A. (2016a). Race as a moderator of associations between spanking and child outcomes. Family Relations, 65(3), 490-501. https://doi.org/10.1111/fare.12205

Gershoff, E. T., \& Grogan-Kaylor, A. (2016b). Spanking and child outcomes: Old controversies and new meta-analyses. Journal of Family Psychology, 30(4), 453-469. https://doi.org/10.1037/ fam0000191

Gershoff, E. T., Grogan-Kaylor, A., Lansford, J. E., Chang, L., Zelli, A., Deater-Deckard, K., \& Dodge, K. A. (2010). Parent discipline practices in an international sample: Associations with child behaviors and moderation by perceived normativeness. Child Development, 81(2), 487-502. https://doi.org/10.1111/j.1467-8624.2009. 01409.x

Herrenkohl, T. I., Leeb, R. T., \& Higgins, D. (2016). The public health model of child maltreatment prevention. Trauma, Violence, and Abuse. https://doi.org/10.1177/1524838016661034

Hillis, S., Mercy, J., Amobi, A., \& Kress, H. (2016). Global prevalence of past-year violence against children: A systematic review and minimum estimates. Pediatrics. https://doi.org/10.1542/peds.20154079

Irwin, L. G., Siddiqi, A., \& Hertzman, C. (2007). Early childhood development: A powerful equalizer: Final report. HELP, University of British Columbia. http://www.who.int/entity/social_determi nants/resources/ecd_kn_report_07_2007.pdf

Jarosz, A. F., \& Wiley, J. (2014). What are the odds? A practical guide to computing and reporting Bayes factors. Journal of Problem Solving. https://doi.org/10.7771/1932-6246.1167

Khaleque, A., \& Rohner, R. P. (2011). Transnational relations between perceived parental acceptance and personality dispositions of children and adults: A meta-analytic review. Personality and Social Psychology Review, 16(2), 103-115. https://doi.org/10.1177/ 1088868311418986

Kruschke, J. K., \& Liddell, T. M. (2018). Bayesian data analysis for newcomers. Psychonomic Bulletin and Review. https://doi.org/10.3 758/s13423-017-1272-1

Lansford, J. E., Alampay, L. P., Al-Hassan, S. M., Bacchini, D., Bombi, A. S., Bornstein, M. H., Chang, L., Deater-Deckard, K., Giunta, L. D., Dodge, K. A., Oburu, P., Pastorelli, C., Runyan, D. K., Skinner, A. T., Sorbring, E., Tapanya, S., Tirado, L. M. U., \& Zelli, A. (2010). Corporal punishment of children in nine countries as a function of child gender and parent gender. International Journal of Pediatric Otorhinolaryngology. https://doi.org/10.1155/2010/ 672780

Lansford, J. E., Chang, L., Dodge, K. A., Malone, P. S., Obuni, P., Palmerus, K., Bacchini, D., Pastorelli, C., Bombi, A. S., Zelli, A., Tapanya, S., Chaudhary, N., Deater-Deckard, K., Manke, B., \& Quinn, N. (2005). Physical discipline and children's adjustment: Cultural normativeness as a moderator. Child Development, 76, 1234-1246.

Loizillon, A., Petrowski, N., Britto, P., \& Cappa, C. (2017). Development of the Early Childhood Development Index in MICS surveys. United Nations Children's Fund (UNICEF), Data and Analytics Section, Division of Data, Research and Policy.

Ma, J., Grogan-Kaylor, A., \& Lee, S. J. (2020). Does community violence exposure moderate the associations between maternal spanking and early child behavior problems? Aggressive Behavior, 46(3), 210-219. https://doi.org/10.1002/ab.21882 
McGlothlin, A., \& Viele, K. (2018). Bayesian hierarchical models. The Journal of the American Medical Association, 320(22), 2365-2366. http://dx.https://doi.org/10.1001/jama.2018.17977

National Scientific Council on the Developing Child (2004). Children's emotional development is built into the architecture of their Brains: Working Paper No. 2. http://www.developingchild.net

Pace, G. T., Lee, S. J., \& Grogan-Kaylor, A. (2019). Spanking and young children's socioemotional development in low- and middle-income countries. Child Abuse \& Neglect, 88, 84-95. https://doi.org/10.1016/j.chiabu.2018.11.003

Pinheiro, P. S. (2006). World report on violence against children. The United Nations Secretary-General's Study on Violence against Children.

R Core Team. (2018). R: A language and environment for statistical computing. https://www.r-project.org/

Stan Development Team. (2018). The Stan core library (Version 2.18.0). http://mc-stan.org

UN Committee on the Rights of the Child (CRC), General comment No. 8. (2006). The right of the child to protection from corporal punishment and other cruel or degrading forms of punishment (Arts. 19; 28, Para. 2; and 37, inter alia), 2 March 2007, CRC/C/GC/8. Retrieved February 14, 2020, from https://www.refworld.org/docid/460bc7772.html

United Nations Children's Fund (UNICEF). (2020). Global status report on prevention violence against children 2020. UNICEF.

United Nations General Assembly. (1959). Declaration of the rights of the child. Author.

United Nations General Assembly. (1989). Convention on the rights of the child. Author.

United Nations General Assembly. (2007). Rights of the child. United Nations 62/141.

Van de Schoot, R., Kaplan, D., Denissen, J., Asendorpf, J. B., Neyer, F. J., \& Aken, M. A. (2014). A gentle introduction to Bayesian analysis: Applications to developmental research. Child Development, 85(3), 842-860. https://doi.org/10.1111/cdev.12169

World Health Organization (2016). INSPIRE seven strategies for ending violence against children. https://www.who.int/publica tions-detail/inspire-seven-strategies-for-ending-violence-againstchildren 